\title{
Dominique Hölzle, Le Roman libertin au XVIII siècle, une esthétique de la séduction
}

\section{Marisa Ferrarini}

\section{(2) OpenEdition}

\section{Journals}

\section{Edizione digitale}

URL: https://journals.openedition.org/studifrancesi/3107

DOI: 10.4000/studifrancesi.3107

ISSN: 2421-5856

\section{Editore}

Rosenberg \& Sellier

\section{Edizione cartacea}

Data di pubblicazione: 1 juillet 2013

Paginazione: 458-459

ISSN: 0039-2944

\section{Notizia bibliografica digitale}

Marisa Ferrarini, «Dominique Hölzle, Le Roman libertin au xvII" siècle, une esthétique de la séduction», Studi Francesi [Online], 170 (LVII | II) | 2013, online dal 30 novembre 2015, consultato il 01 février 2023. URL: http://journals.openedition.org/studifrancesi/3107 ; DOI: https://doi.org/10.4000/studifrancesi. 3107

Questo documento è stato generato automaticamente il 1 février 2023.

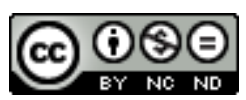

Creative Commons - Attribuzione - Non commerciale - Non opere derivate 4.0 Internazionale - CC BYNC-ND 4.0

https://creativecommons.org/licenses/by-nc-nd/4.0/ 


\title{
Dominique Hölzle, Le Roman libertin au XVIII siècle, une esthétique de la séduction
}

\author{
Marisa Ferrarini
}

\section{NOTIZIA}

DOMINIQUE HÖLZLE, Le Roman libertin au XVIII siècle, une esthétique de la séduction, Oxford, Voltaire Foundation, SVEC 2012:05, pp. 286.

1 Nel cercare di definire la specificità del romanzo libertino del XviII secolo, Dominique Hölzle opta, come indica il titolo, per l'estetica della seduzione. I seduttori sono parecchi nei romanzi galanti e nei romanzi libertini mondani, tant'è che è assai difficile distinguere nettamente le due tradizioni romanzesche. Tutti i romanzi libertini si svolgono in ambienti aristocratici e mettono in scena tentativi di seduzione che hanno a che vedere con l'universo della galanteria, nozione sociale, morale ed estetica, oggi di moda, che invita a ripensare i generi letterari dell'età classica. Ecco perché, afferma l'autore nell'introduzione, i romanzi libertini appaiono più come un ramo del genere galante che come un genere autonomo. Se differenza c'è, questa risiede nella critica più sistematica che il romanzo libertino esercita sui difetti della mondanità e nella predominanza del punto di vista maschile. È a questo punto che entra in gioco la figura del roué, lo scellerato metodico, che si differenzia dagli altri personaggi per capacità di riflettere, consapevolezza della propria corruzione, volontà di pervertire il gioco della galanteria per rendere manifesta l'universale falsità dei comportamenti. I roués praticano con esultanza la dissimulazione e la menzogna per ingannare e umiliare le proprie vittime. Si presentano come detentori di un sapere che si fonda sull'idea dell'ipocrisia femminile e il cui obiettivo è scalzare la donna dal posto che occupa nella società aristocratica. Si caratterizzano per il gusto per la teoria, ma anche per la ricerca costante dell'originalità e a tale titolo non esitano a ostentare una crudeltà inedita. Il 
modo in cui integrano problematiche estetiche nell'elaborazione del proprio personaggio è un altro tratto distintivo. I roués creano immagini affascinanti e mobili di se stessi attraverso un lavoro di citazioni, pastiches, rovesciamenti parodici. Questo gioco sui discorsi e le immagini di sé acquista senso alla luce della relazione estetica che intendono stabilire con i loro complici e in particolare con il pubblico. La mobilità delle immagini di sé, il gusto per i comportamenti trasgressivi, l'idea della gloria permettono di ridurre le relazioni intersoggettive a un rapporto di «éclat et subjugation» (p. 254). Le seduzioni dei roués diventano così pretesto all'elaborazione di racconti che proporranno ai loro complici e che mirano a fare delle vittime, dei cui tormenti si diletteranno, eroine da romanzo. Questa volontà di «mise en fiction» presuppone che le vittime siano delle «belles-âmes», donne votate al sentimento, sincere e virtuose, sul modello della Clarissa Harlowe di Richardson. Di conseguenza, i tentativi di seduzione diventano esperienze estetiche grazie a dispositivi complessi che tendono ad accentuare la teatralità delle situazioni. La lettera assume un ruolo centrale nell'elaborazione di tali dispositivi. I roués utilizzano, infatti, la corrispondenza per presentarsi come demiurghi, infaticabili produttori di «fictions», come attori capaci di dominare le proprie passioni sull'esempio del Paradoxe sur le comédien di Diderot, ma anche per godere da spettatori delle scene che ricreano. Si produce però un fenomeno destabilizzante: non appena i roués iniziano a descrivere le sofferenze della «belleâme», s'immobilizzano in quadri patetici che non controllano più e da cui sono affascinati. Questo fenomeno rivela una tensione poetica che anima le lettere dei roués. Concepite in funzione di una poetica libertina, vicina a quella degli autori galanti, esse sono costantemente influenzate da una poetica della sensibilità che colloca i loro autori in un aldilà del linguaggio. Tale fenomeno ci riconduce alla questione dei generi. Se i romanzi libertini mondani s'iscrivono nella continuità della novella galante e rispettano, nel complesso, una poetica ereditata dal secolo precedente, i romanzi dei roués sono caratterizzati dalla presenza di un'estetica della sensibilità, influenzata da Richardson e Rousseau, che inaugura una nuova scrittura. 